\section{SOLMIZAÇÃO: REGRAS PARA A NOMEAÇÃO \\ DAS NOTAS DE ACORDO COM AUTORES INGLESES NO SÉCULO XVII}

Nathália Domingos ${ }^{1}$

\section{RESUMO:}

Este artigo tem como objetivo evidenciar as regras propostas pelos autores ingleses para a correta nomeação das notas durante a solmização por meio de três tratados seiscentistas representativos: A nevv vvay of making fowre parts (c. 1613) de Thomas Campion; An Introduction to the skill of musick in two books (1655) de John Playford e A compendium of practical musick (1667) de Christopher Simpson.

\section{PALAVRAS-CHAVE:}

teoria musical inglesa; solmização; século XVII.

\section{ABSTRACT:}

The present paper aims to show the rules proposed by English authors to the correct naming of notes during the solmization by means of three representative treatises seventeenth century: The Nevv vvay of making fowre parts (1613 c.) by Thomas Campion; An Introduction to the skill of musick in two books (1655) by John Playford and A compendium of practical musick (1667) by Christopher Simpson.

\section{KEYWORDS:}

English music theory; solmization; seventeenth century.

Sabe-se que o desenvolvimento de métodos de solmização, a partir do século XI, amenizou a dificuldade do ensino e da aprendizagem de cançóes. Ao contrário do solfejo atual no qual cada uma das sete notas musicais possui a sua respectiva sílaba (dó-ré-mi-fá-sol-lá-si), a solmização utiliza apenas seis

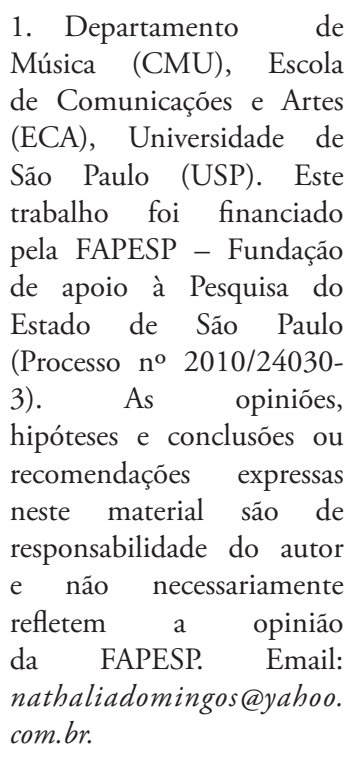

1. Departamento de Música (CMU), Escola de Comunicaçóes e Artes (ECA), Universidade de São Paulo (USP). Este trabalho foi financiado pela FAPESP - Fundação de apoio à Pesquisa do Estado de São Paulo (Processo no 2010/240303). As opinióes, hipóteses e conclusōes ou recomendaçóes expressas neste material são de responsabilidade do autor e náo necessariamente refletem a opinião da FAPESP. Email: nathaliadomingos@yahoo. com.br.

?


(ut, ré, mi, fá, sol, lá) organizadas em três diferentes Deduçóes (ou hexacordes) com início em C, G e F.

As Deduções, cujo padrão intervalar consiste em Tom-Tom-Semitom-Tom-Tom, eram classificadas em naturalis (início em C), b durum (início em G), $b$ molle (início em F).

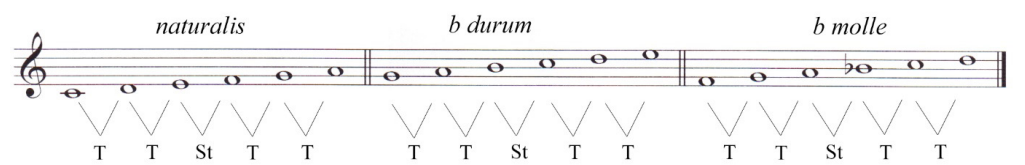

Fig. 1. Classificação das Deduçôes (hexacordes).

Em geral, as melodias ultrapassavam o intervalo de uma sexta e o cantor deveria fazer a mutação para prosseguir solmizando acima do lá ou abaixo do ut.

A mutação é o processo de abandonar uma Voz (sílaba) de uma determinada Deduçáo e adotar outra com a mesma altura sonora, mas pertencente a outra Dedução. Isto é possível porque cada nota, ou seja, cada altura sonora possui duas ou mais Vozes associadas a ela, como pode ser visualizado na Figura 2.

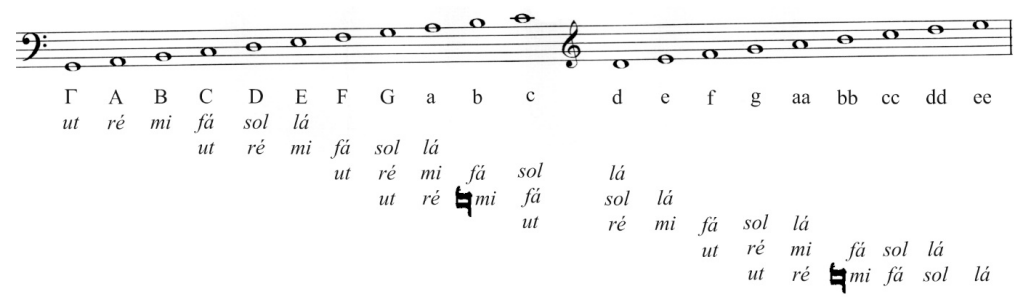

Fig. 2. Altura real das notas e suas respectivas sílabas de solmização.

As letras determinam a altura real da nota, enquanto as sílabas são ferramentas que permitem a correta relação intervalar durante a solmização, visto que os semitons recaem entre as Vozes mi-fá.

De forma geral, no continente, a mutação ocorria na sílaba ré nas melodias ascendentes e na Voz lá nas melodias descendentes. Por outro lado, no século XVII na Inglaterra, a solmização difere daquela praticada no continente europeu. Em primeiro lugar, os ingleses utilizavam um sistema que continha apenas quatro sílabas $(m i, f a ́, s o l, l a ́)$ que não estava baseado nas Deduçóes (hexacordes). Sendo assim, as mutaçóes não eram requisitadas e outros procedimentos eram utilizados 
para que o aprendiz nomeasse corretamente as notas durante a solmização.

A seguir, serão evidenciadas as regras propostas pelos autores ingleses durante o século XVII para a correta nomeação das notas a partir de três autores representativos: Campion, Playford e Simpson.

\section{THOMAS CAMPION (C. 1613)}

Para Campion (c. 1613, $f$ B4 a), o verdadeiro conhecimento da escala consiste na observação do semitom que é expressado por mi-fá ou lá-fá. Ao identificar os semitons, as demais Vozes são acomodadas sequencialmente em seus devidos lugares.

Segundo Campion (c. 1613, $f$ B5 a), "acima de fá sempre cante sol; e sempre cante sol abaixo de lá".

$$
\text { sol-lá-mi-fá-sol-lá-fá - sol-lá-mi-fá-sol-lá-fá -etc. }
$$

Para explicar a solmização, Campion (c. 1613, $f$ B4 a) apresenta três escalas que começam no Signo $\Gamma$ ut (Figura 3). A primeira não possui alteração no início da clave; a segunda escala contém um bemol no Signo $\mathbf{b}_{f a ́}$ mi, ao passo que a última tem dois bemois: um deles no Signo $\mathbf{b}_{f a ́}$ mi e o outro em E lá mi. Observe que a sequência das sílabas muda de acordo com os sinais dispostos no início do pentagrama devido ao posicionamento dos semitons.

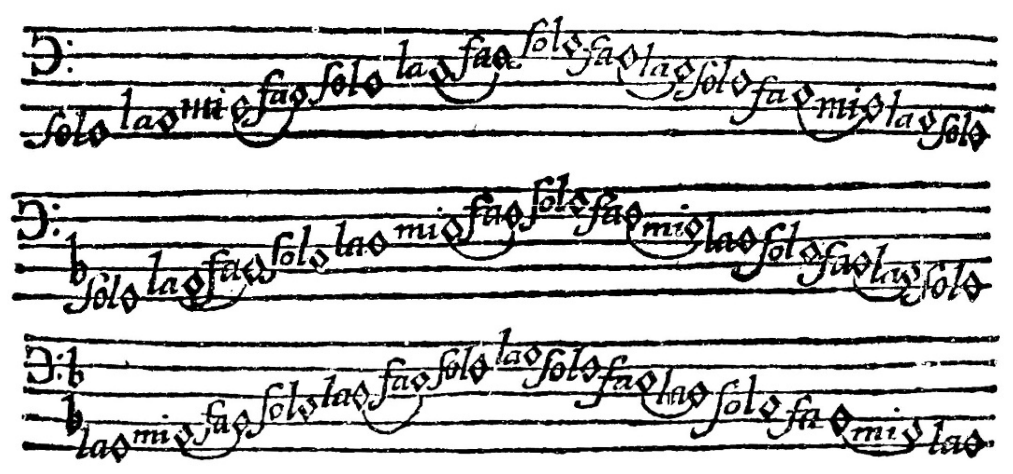

Fig. 3. Solmização de escalas com diferentes armaduras (CAMPION, c. $1613, f \mathrm{~B} 4 \mathrm{v}-f \mathrm{~B} 5 \mathrm{a})$. 
Como pode ser observado no exemplo acima, as sílabas $u t$ e ré não são requisitadas. Além disto, se o semitom inferior for mi-fá, o semitom superior será lá-fá e vice-versa.

Em suma, para Campion, o importante é observar as localizaçóes dos semitons que estão marcados pelos semicírculos em seus exemplos.

\section{JOHN PLAYFORD (1665)}

Playford, por outro lado, estabelece regras para a localização da Voz mi:

Em primeiro lugar, observa que o $m i$ é a Voz mestre ou a mais importante que te leva a conhecer todas as outras Vozes. Tendo descoberto o $m i$, as outras Vozes seguem um percurso. Este $m i$ tem sua existência em quatro lugares diferentes, mas está em apenas um destes lugares a cada vez. Seu local característico é em $\mathrm{B} m i$, mas se um B $f a ́$, assim como um bemol [...] estiver colocado naquele lugar, o mi é posicionado em E lá mi, que é o segundo lugar. Entretanto, se um bemol também estiver colocado ali, o mi estará em seu terceiro local que é A lá mi ré. Se um bemol aparecer também ali, então o mi é transferido para sua quarta posição que é $\mathrm{D}$ lá sol ré, de modo que em qualquer um destes lugares que o mi estiver, as próximas Vozes ascendentes acima dele são fá-sol-lá, fá-sol-lá até encontrar teu mi novamente, pois ele aparece apenas uma vez no intervalo de oito notas. Da mesma forma, as próximas Vozes abaixo dele são lá-sol-fá, lá-sol-fá até encontrar novamente teu mi (PLAYFORD, 1655, p. 11-12).

Portanto, a sílaba mi pode ser acomodada em quatro locais:

* Signo b fá mi (sem sinal na armadura de clave);

* Signos E lá mi, e lá mi, ee lá (um bemol);

* Signos A ré, a lá mi ré, aa lá mi ré (dois bemois);

* Signos D sol ré, d lá sol ré, dd lá sol (três bemois).

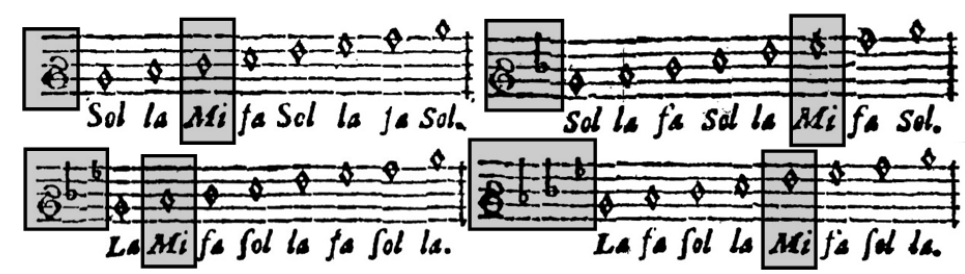

Fig. 4. Posicionamento do mi (PLAYFORD, 1655, p. 11-12). 
O correto posicionamento da sílaba mi permite, consequentemente, o conhecimento das demais Vozes, visto que acima dele temos duas vezes a sequência fá-sol-lá, enquanto abaixo dele, duas vezes lá-sol-fá, assim:

fá-sol-lá-fá-sol-lá-MI-fá-sol-lá-fá-sol-lá-MI- etc.

Como consequência, as sílabas pronunciadas no intervalo de uma oitava são idênticas, uma vez que náo há a utilização das sílabas ut e ré.

\section{CHRISTOPHER SIMPSON (1667)}

Assim como os autores precedentes, Simpson também adota apenas quatro sílabas para o ensino da solmização:

Quatro destas [sílabas], mi, fá, sol, lá (compreendidas em sua plenitude), são auxiliares indispensáveis para a correta afinação dos graus sonoros, como será visto em breve. As outras duas, ut e ré, são supérfluas e, portanto, ignoradas pela maioria dos professores contemporâneos. Usaremos, portanto, apenas $m i$, fá, sol, lá nas sete letras que representam os graus sonoros. Para isto, primeiramente precisamos descobrir onde o mi deve ser colocado. Uma vez descoberto, os lugares das outras três [sílabas] são consequentemente conhecidos, já que mi tem sempre fá, sol, lá acima e abaixo dele [...] (SIMPSON, 1667, p. 5).

Para Simpson, a sílaba mi pode ser acomodada em 3 locais:

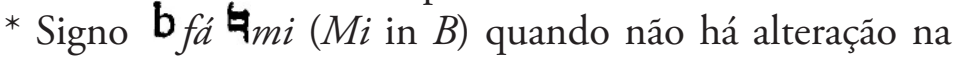
armadura de clave;

* Signo E lá mi $(M i$ in $E)$ quando há um bemol na clave;

* Signo A ré $(M i$ in $A)$ quando há dois bemois.

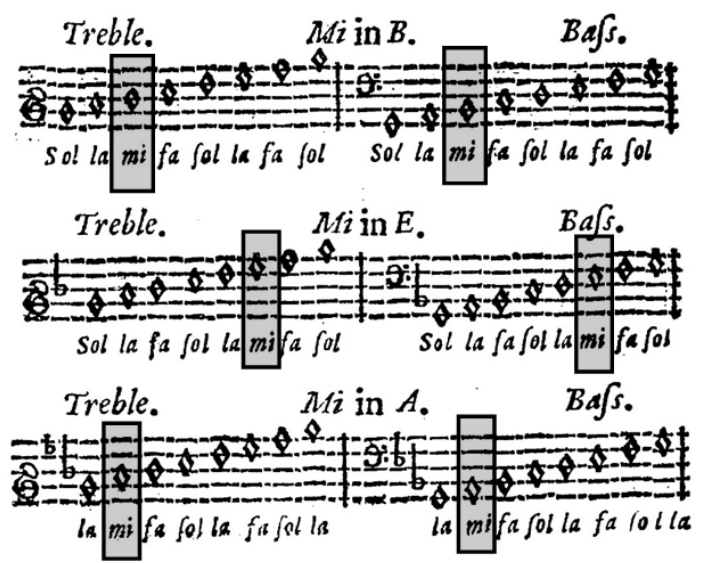

Fig. 5. Posicionamento do mi (1667, p. 11). 
Além disto, Simpson (1667, p. 6) menciona a existência de cançóes que apresentam três bemois na armadura de clave. De acordo com o autor,

Já vi cançốes com bemois localizados em A, B, e E simultaneamente; desta forma o mi é deslocado de seus três locais, mas tais cançóes são irregulares [...] sendo designadas para instrumentos ao invés de vozes. No entanto, se alguma de tais cançóes for apresentada, posicione teu $m i$ em D com fá, sol, lá acima e abaixo dele [...] (SIMPSON, 1667, p. 6).

Apesar de mencionar a existência de cançóes com três bemois, Simpson não exibe em seu tratado nenhum exemplo para a solmização. Entretanto, caso o aprendiz se depare com uma melodia com estas características, o autor elucida que o mi deve ser posicionado em d lá sol ré para que náo haja problemas na solmizaçáo (Figura 6).

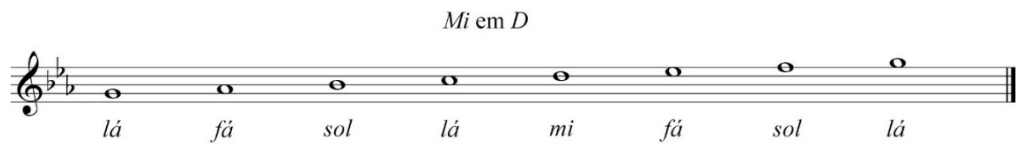

Fig. 6. Mi em D - três bemois na armadura de clave.

\section{CONSIDERAÇÓES FINAIS}

O estudo da solmização permite entender a teoria e a prática musicais daquele período, uma vez que as composiçóes eram baseadas neste sistema.

Apesar de ter o mesmo fundamento no método que se difundiu por toda Europa a partir do século XI, os ingleses, durante o século XVII, ensinavam a solmização por meio de regras peculiares. Para Campion (c. 1613), o importante é conhecer a localização do semitom expresso pelas sílabas mi-fá ou lá-fá. Já Playford (1655) e Simpson (1667) ensinam os estudantes a posicionarem corretamente a Voz mi e, como consequência, as demais sílabas são acomodadas automaticamente.

Apesar destes autores exibirem métodos diferentes para o seu ensino, as sílabas empregadas durante a solmização recaem nas mesmas notas, como pode ser visualizado a seguir: 


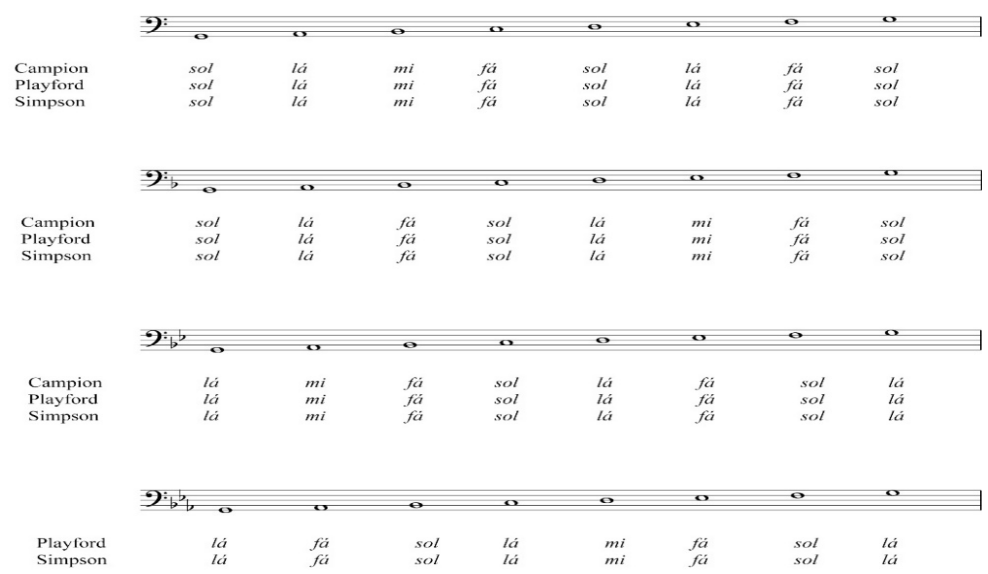

Fig. 7. Quadro comparativo da solmização nos diferentes autores ingleses.

Conclui-se que apesar dos teóricos exibirem uma didática para o ensino de solmizaçáo que apresenta características distintas (localizaçáo do semitom e o posicionamento da Voz mi), o resultado observado após a comparação da solmização nos três tratados é idêntico.

Isto se deve principalmente porque os ingleses, diferentemente dos autores continentais, utilizam apenas quatro sílabas: $m i$, fá, sol, lá. Com isto, a sílaba de solmização que qualquer nota recebe é a mesma uma oitava acima ou abaixo e os semitons ocorrem entre as Vozes mi-fá e lá-fá no intervalo de uma oitava.

Em suma, este sistema desenvolvido e adotado pelos ingleses durante o século XVII facilita o aprendizado da solmizaçáo, uma vez que náo é exigido do jovem aprendiz o processo de mutação.

\section{REFERÊNCIAS BIBLIOGRÁFICAS}

CAMPION, Thomas. A nevv vvay of making fowre parts in Counter-point, by a most Familiar, and infallible Rule. Secondly, a necessary discourse of Keyes and their proper Closes. Thirdly, the allowed passages of all Concords perfect, or imperfect, are declared. Also by way of Preface, the nature of the Scale is expressed, with a briefe Method teaching to Sing. London: T[homas] S[nodham], c. 1613. (14f).

PLAYFORD, John. An Introduction to the Skill of Musick in two books. London: John Playford, 1655 (129f.). 
SIMPSON, Christopher. A compendium of practical musick in five parts: teaching, by a New, and easie Method, 1. The Rudiments of Song. 2. The Principles of Composition. 3. The Use of Discords. 4. The Form of Figurate Descant. 5. The Contrivance of Canon. London: William Godbid for Henry Brome, 1667 (176p.). 